УАK 323

ББК 66.3(0)

DOI 10.22394/1682-2358-2019-3-12-23

I.M. Ponyaev, Lecturer of the International Organizations and World Political Processes Department, Lomonosov Moscow State University

\section{THE MODEL OF SOCIO-POLITICAL TRANSFORMATIONS DURING CRISES OF DUAL POWER}

The model of socio-political transformations in the emergence, development and end of dual power crises is presented. The conditions of their occurrence are specified. The paper is based on the analysis of three modern dual power crises known in political science.

Key words and word-combinations: conflict of dual power, political crisis, social and political transformations.
И.М. ПоняеВ, преподаватель кафедрог международньхх организаиий и мировьх политических прочессов Московского государственного университета имени М.В. цомоносова (email: ponyaevi92@mail.ru)

\section{MO $\triangle \mathrm{E} \Lambda \mathrm{b}$ СОЦИААЬНО-ПОАИТИЧЕСКИХ ТРАНСФОРМАЦИЙ В ПЕРИОАЫ КРИЗИСОВ АВОЕВ $\Lambda$ АСТИЯ}

Аннотация. Представлена модель социальнополитических трансформаций при появлении, развитии и окончании кризисов двоевластия. Специфицируются условия их возникновения. Работа основана на анализе трех известных в политической науке современных кризисов двоевластия.

Ключевые слова и словосочетания: конфликт двоевластия, политический кризис, социальнополитические трансформации.

$\mathrm{B}$ политические кризисы и конфмикты неразрывно связаны с социальнополитическими трансформациями. Такие трансформации могут предшествовать помитическому кризису, происходить в процессе его развития или после окончания. Кризис Авоевластия отмичается тем, что преАполагает одновременную мегитимность Авух ветвей власти, борющихся межАу собой за политическое Аоминирование в стране $[1$, с. 1352]. В иных политических кризисах возможно четко разделить 
Аействующую власть и оппозицию, которая стремится ее получить, при этом действует односторонняя мегитимность власти и насилия [2, с. 120], применяемая официальной вмастью. Так, если политические силы, находящиеся у власти, применяют насилие дяя защиты своих интересов, власти и ресурсов, это считается кегитимным, кегальным и законным, а использование аналогичных инструментов оппозицией явмяется преступмением. При кризисах Авоевмастия использование насилия мегитимно Аля обеих сторон. Именно поэтому во время подобных конфциктов так важны реальная подлержка населения и оправдание использования насилия вцастью с точки зрения разделения соџиально-политических иАей и взглядов.

Еще одним принципиальным отличием чертой кризисов двоевластия явмяется то, что нередко они затухают, переходя в скрытую фазу, а потом вспыхивают вновь [3, с. 1785]. По сути, один и тот же конфликт периодически может возникать в обществе как совершенно новое явление в процессе продолжающегося кризиса. Определить, что данный кризис - продолжение предылущего, можно по нескольким особенностям. Во-первых, конфликт двоевластия преАполагает сушествование оппозиционных мнений внутри действуюшей власти, одна из ветвей которой в проџессе развития кризиса может стать неформальной оппозиџией, однако ключевые политические взгляды каждой стороны должны оставаться неизменными или постепенно эволюционировать. Во-вторых, обе стороны должны иметь мегитимные претензии на власть, хотя бы в один из моментов развития конфиикта [4, с. 392], связанных с Аругими событиями кризиса.

В настоящее время весьма актуально изучение специфики кризисов двоевластия, выявление их отличительных особенностей, а также формализация обшей модели развития, включаюшей формирование, развитие и окончание кризиса.

В мировой политической жизни, начиная с 1990-х годов, известны три покитических кризиса двоевластия: первый - кризис 1993 г. в России; второй - в Аивии, начавшийся в 2011 г. при свержении М. Каддафи; третий - в Венесуэле, начавшийся в 2015 г., когда парламент предпринял попытку отстранения президента от власти. Каждый из этих кризисов имеет характерные особенности, но существуют общие дяя всех них принщипы, которые систематизированы в Аанной работе. Крайне сложно выявить закономерности окончания кризиса Авоевцастия, так как из трех кризисов завершенным явцяется кишь один.

Аля реализации и обеспечения достоверности данного исследования используются метод систематизации, позволяющий обобщить в еАиную модель кризиса двоевластия разрозненные политические события, происходившие в различных странах в разное время, и институциональный метоА, при котором выдемяют основных участников конфмикта, а также специфиџируют ключевые процессы социально-политической трансформации в обществе, включая формальные и неформальные институты и отдельные взгляды значимых социальных групп. В качестве базы исследования используется упорядоченная хронология кАючевых событий рассматриваемых конфликтов Авоевластия, включая характеристику политической ситуаџии и динамику ее изменений в наиболее значимых моментах. 
Первым анализируемым кризисом двоевластия явмяется политический кризис в России в 1993 г., неразрывно связанный с распадом СССР и институциональными изменениями в обшестве, происходившими в проџессе его миберализаџии. Кмючевым политическим мотивом конфмикта выступала разниџа во взглядах на разумный уровень демократизации и миберализации общества [5, с. 205], а конфликтом двоевластия он фактически стал 24 апреля 1991 г., когда Верховный Совет РСФСР принял Закон РСФСР «О президенте РСФСР». 9 декабря 1992 г. VII СъезА народных депутатов РФ существенно расширил полномочия парламента, переведя конфликт в открытое противостояние законодательной и исполнительной власти. В конџе марта 1993 г. президент РФ и российский парламент перешки к активной фазе противостояния, что привело к необходимости референдума, так как политическая ситуаџия зашла в тупик. Отметим, что к этому времени развивающийся конфликт перешел из общественного во внутриэлитный. Референдум в такой ситуаџии стал попыткой возврашения конфликта на общенародный уровень. Каждая сторона стремилась сформировать общественное мнение выгодным ей образом, однако определяющим моментом являлся факт трансформаџии соџиально-политических взглядов населения в проџессе развития конфмикта. Тем не менее референдум продемонстрировал, что ни одна из сторон не преуспела в данном процессе. Таким образом, важнейшим фактором пролонгирования конфликта двоевластия явцяется отсутствие политической определенности у большинства населения.

Кульминацией противостояния исполнительной и законодательной власти стали события 21 сентября 1993 г. Президент Б.Н. Ельцин издал Указ № 1400 об установлении мегитимности искмючительно собственной власти и роспуске парламента. В свою очередь, Х СъезА народных депутатов и Верховный Совет РФ преАприняли попытку отстранения президента от должности. Конституционный Суд России поддержал президента, в результате чего произошиа кульминация противостояния исполнительной и законодательной власти, фактически отстранивших Аруг Аруга от занимаемых домжностей [6, с. 458] . При этом среди политиков доминировали ценности сохранения кичной власти, а не развития обшества. По сути, политический конфмикт идей перешел в борьбу за власть и ресурсы.

Конфиикт сентября - октября 1993 г. в России разрешияся с применением военной силы. Несмотря на малое число военных действий, их роль в завершении данного конфмикта стала опредемяющей. Произошло утверждение главенства президентской вмасти, закрепленное Конституџией РФ от 12 декабря 1992 г. [7, с. 46] (рис. 1). Подчеркнем, что разрешению политического конфликта способствовало неприменение насилия. Окончание конфликта Авоевластия ознаменовало принятие на референдуме 12 декабря 1993 г. новой Конституции РФ, а также формирование нового парламента на общенациональных выборах.

Таким образом, важнейшие трансформации во время политического кризиса двоевластия в России произошии не столько на внутриэлитной политической арене, сколько на общественной. 


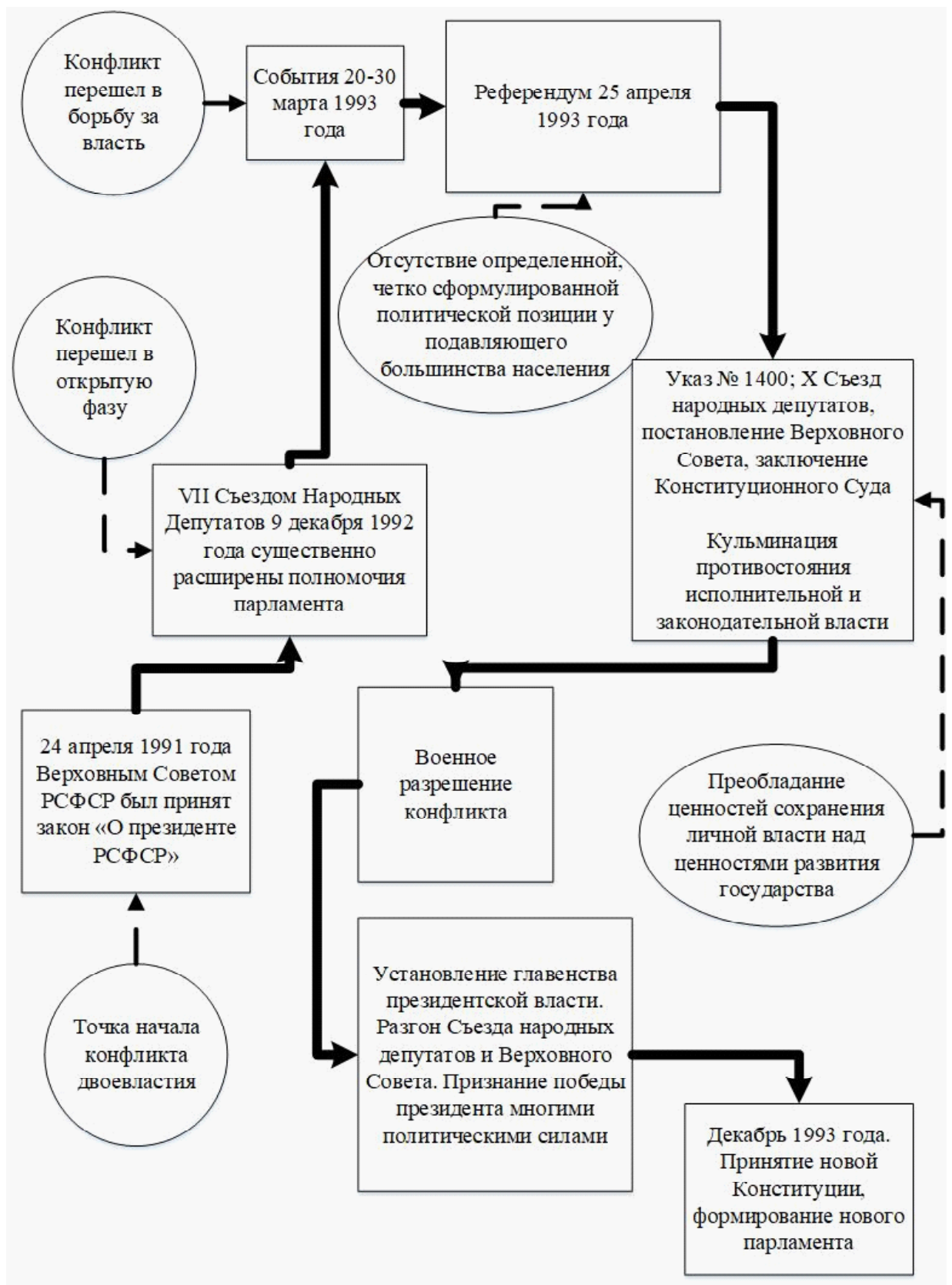

Рис.1. Развитие конфликта Авоевластия в России 
Население, которое еще в апреле поддерживало и Президента РФ, и парламент, выразило одобрение различных реформ, предлагаемых президентом. В результате парламент, оставшийся без фактической подАержки, не мог продолжать политическую борьбу. Кроме того, Б.Н. Ельцин вошел в историю России как харизматичный кидер, а у парламента мидеров такого уровня не было. КажАый из них имел значительный политический вес, но не обладац существенным влиянием на массы и соответствующим уровнем подаержки.

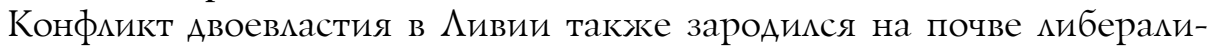
зации и демократизаџии общества. Первоначально он возник между М. КадАафи и Переходным национальным советом, являвшимся временным парламентом, принимаемым ООН [8, с. 82]. Поскольку поддержка Переходного национального совета как населением, так и международным сообшеством была существенно выше, чем у М. Каддафи, первый этап кризиса продлияся около полугоАа, после чего политический кризис двоевластия находияся в состоянии затишья почти три года. Все политические конфликты фактически решались внутри выбранного всенародным голосованием Всеобщего национального конгресса [9, с. 316] . Ситуация начала обостряться в тот момент, когда в этом органе власти доминирующую роль стали играть радикально настроенные исламисты, которые впоследствии отказались передать власть Палате представителей. В результате в июне 2014 г. в Аивии начался новый виток кризиса двоевластия (рис. 2).

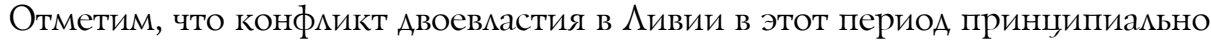
отличался от событий в России в 1993 г. по нескольким аспектам. Во-первых, органы государственной власти фактически дублировали Аруг Аруга: это был конфликт не Авух ветвей власти, а Авух конкурирующих парламентов. Вовторых, влияние в стране имело четко выраженные географические границы: Всеобщий нащиональный конгресс контролировац западную часть страны, а Палата преАставитекей - восточную.

Следующие полтора года вкмючали в себя множественные раунды межмивийских переговоров, в результате которых было подписано соглашение о формировании Правительства наџионального единства. Аанное правительство Аолжно было остановить конфцикт Авоевластия, став еАинственным кегитимным парламентом, однако Всеобщий национальный конгресс передал ему свои полномочия, а Палата представителей отказалась. Произошла замена сторон в конфцикте двоевластия, продолжавшем активно развиваться в цивийском обществе. С Палатой преАставителей объединиц свои силы генерал Х. Хафтар, активно реализующий собственные политические интересы через военные действия. В результате военная часть противостояния усицикась, а политическая дискуссия свелась к минимуму; общество, проходящее проџесс трансформаџии кАючевых политических идей и взгляАов, оказалось втянуто в военные действия, которые не способствуют политической эволюџии. 


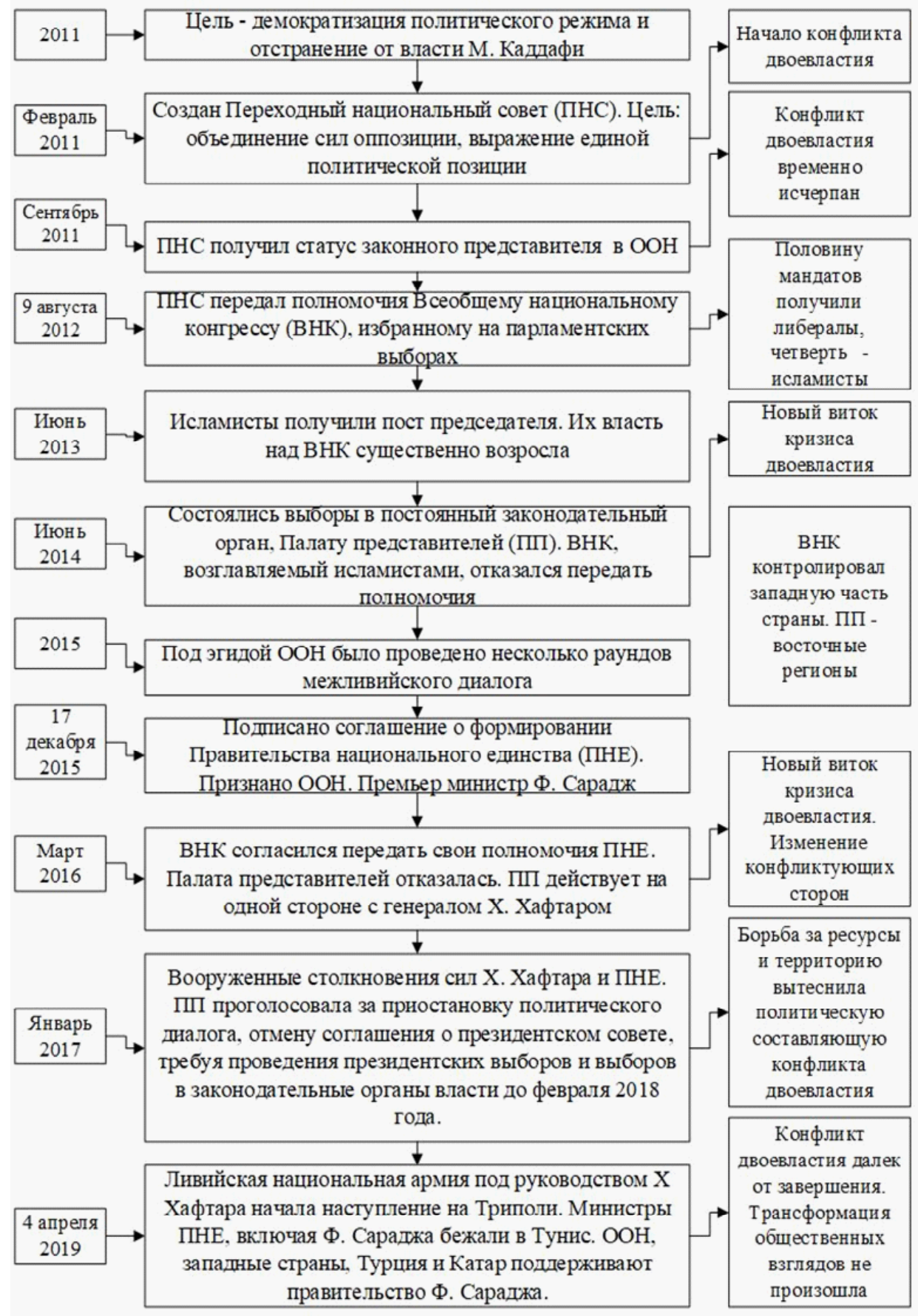

Рис. 2. Развитие конфликта двоевластия в Аивии 
В январе 2017 г. Палата представителей стала предпринимать активные политические шаги и действия, направленные на мишение мегитимности Паматы национального единства. Тем не менее конфликт продолжил развиваться в военном ключе и весной 2019 г. министры Палаты национального единства сбежкали из Аивии в Тунис.

На Аанный момент конфликт двоевластия в Аивии нельзя считать завершенным по рялу причин. Во-первых, не произошла трансформаџия политических взглядов большинства населения: страна находится в состоянии противоречия межАу ииберальными взглядами, поддерживаемыми западным обществом, и традиџионными, связанными с исламом. Во-вторых, внутри страны наблюдается явное преобладание сил Х. Хафтара, однако международное сообщество в большинстве поддерживает Палату национального единства, в связи с чем невозможно определить реальный уровень ресурсов каждой стороны. Отметим, что у стороны Палаты преАставителей есть сильный харизматичный $\Lambda$ Аер, коим не обладает вторая сторона конфликта. Его наличие в сложившейся ситуаџии явцяется важным политическим преимушеством.

Конфиикт авоевластия в Венесуэле имеет прежде всего политический характер несмотря на то что оппозиџия, объединившаяся в парламент, борется с президентом, имеющим почти неограниченные полномочия. Кризис начался как кАассический политический конфликт действующей власти и оппозиџии в 2014 г. и перерос с кризис Авоевластия в декабре 2015 г., когда оппозиция помучила парламентское большинство. Первопричиной конфликта стал крайне низкий уровень жизни населения (более половины населения страны живут за чертой бедности) и высокий уровень преступности. Основным доходом Венесуэлы является добыча нефти, и обвал цен на мировых рынках усугубил положение дел внутри страны. В результате одним из мошнейших политических инструментов влияния стал контроль наА распределением гуманитарной помощи.

В конфмикте двоевластия Верховный суд поддержал президента и решил оппозицию квалифиџированного большинства в парламенте в январе 2016 г. [10, с. 893]. В апреле того же года парламент сократил срок президентского мандата с шести до четырех мет, а также инициировал проџеАуру импичмента. ОАнако затягивание проџедуры проведения референдума избирательной комиссией привело к тому, что его политическая значимость фактически свелась к минимуму, так как даже в случае успеха президент передаст свои полномочия выбранному им преемнику или виџе-президенту. Отметим, что в 2015 г. полномочия президента в Венесуэле значительно превышали полномочия парцамента, что существенно ограничивало последний в его действиях.

25 октября 2016 г. парламент проголосовац за начало проџеАуры импичмента президента, однако тот обратился за политической подАержкой к Ватикану, в результате чего из-под стражи были выпушены пятеро политических заключенных, а парламент остановиц свои действия в данном направлении. Считается, что в этот период Венесуэка была наиболее близка к гражданской войне.

ОАнако уже 30 марта 2017 г. президент и поддерживающий его Верхов- 
ный совет Венесуэлы начали активные действия: Верховный совет принял на себя полномочия парламента, а президент подписал указ о формировании альтернативного парламента - Учредительного собрания. Оппозиция отказалась избираться в альтернативный парцамент, поскольку он изначально учрежАался как подконтрольный президенту. В итоге Учредительное собрание, начавшее работу метом 2017 г., отстранимо генерамьного прокурора Венесуэмы, провозгласимо себя высшим органом власти и мишимо мегитимности национальную ассамблею к 18 августа 2017 г. [11, с. 93] . Отметим, что первоначально конфцикт двоевцастия в Венесуэле развивался между президентом и паркаментом, но со временем он привец к возникновению Аублирующих органов вцасти в одной стране.

Такое Аавление со стороны президента, а также аресты наиболее влиятельных мидеров оппозиции привели к ее расколу. Именно этот момент был выбран Н. Мадуро, одержавшим уверенную победу в конфликте двоевластия, по сути мишив мегитимности и политической дееспособности Национальную ассамблею, дмя переизбрания в должности президента (рис. 3).

В начале 2019 г. председателем Наџиональной ассамблеи был избран 35-цетний Х. Гуайдо. Под его руководством парламент снова стал играть важную роль в политике Венесуэлы. Председатель смог не только получить подАержку международного сообщества, но и объединить оппозищию, привлечь сторонников среди наиболее значимых соџиальных групп, включая военных, а также начать действия в области контромя наА распредемением гуманитарной помощи. Кроме того, парламент поА руководством сильного мидера сформировал юридические обоснования нелегитимности власти, в том числе за счет множественных нарушений в процессе проведения выборов.

Конфцикт Авоевластия в Венесуэле далек от завершения и сегодня преАставцяет собой борьбу за распреденение гуманитарной помощи и мояльность военных, явмяющиеся ключевыми ресурсами влияния на население (рис. 3).

Систематизируя представленные сџенарии развития конфликта двоевластия, возможно сформулировать несколько ключевых особенностей формирования, развития и завершения данного типа конфликтов.

Во-первых, началом конфликта Авоевцастия всегда является трансформаџия соџиально-политических идей значительной части общества. Чаще всего это происходит за счет привнесения новых конџепџий в устоявшийся соџиум. В приведенных примерах речь идет о привнесении и развитии идей миберамизма и демократии, которые явмяются доминируюшими сегодня в западных странах, проводящих политическую экспансию, поэтому сами конџепџии миберализма и демократии останутся за рамками данного исследования. Отметим кишь то, что их проникновение в представленные страны во многом детерминировано влиянием внешнего мира, а также то, что эти концепции сталкиваются и конфциктуют с традиционными Аля каждой из изученных стран. Таким образом, первоначально в социуме формируется конфликт на уровне идей, каждая из которых находит выражение в политике определенной группы. 


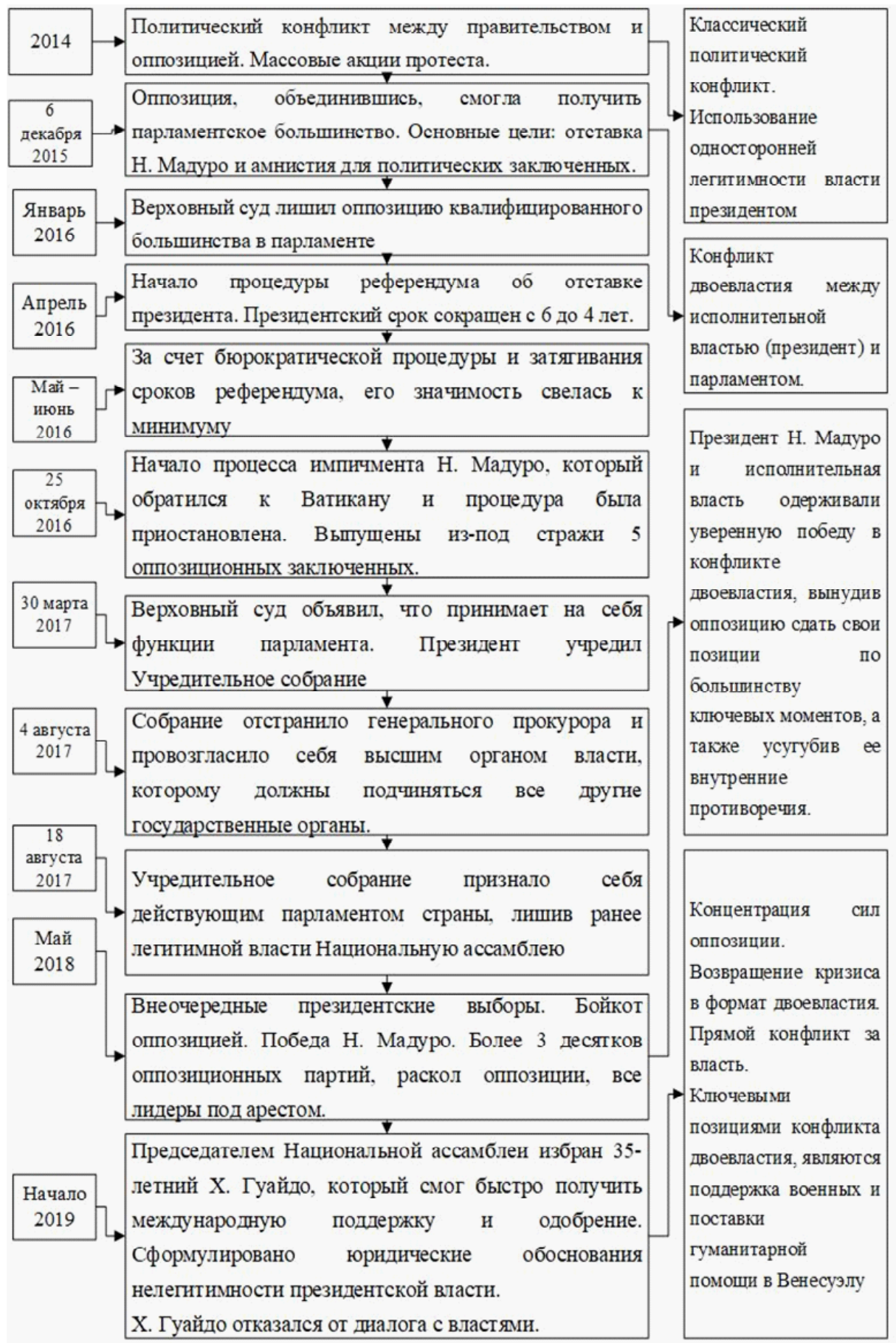

Рис. 3. Развитие конфликта двоевластия в Венесуэле 
Во-вторых, формальный конфмикт двоевластия начинается мишь в том случае, когда разные институты власти начинают придерживаться различных политических позиџий, что часто детерминировано конфликтом идей. Конфликт может протекать как межАу Авумя существующими ветвями власти, так и предполагать формирование новых, в том числе Аублирующих. В большинстве случаев в конфликт Авоевластия вовлечен парламент страны, при этом конфликт обязательно переходит из конфликта идей в борьбу за власть и ресурсы. В проџессе его развития важную роль играет подАержка военных: по сути, именно она часто явмяется определяющей при завершении ици временной приостановке конфцикта. Таким образом, конфликт соџиально-политических идей разрешается за счет трансформаџии позиџии наиболее значимой соџиальной группы. Вместе с тем предполагается, что власть фактически тождественна контролю и возможности применения насилия. Обычно в подобных конфликтах обе стороны имеют возможность применения насилия, а побеждает та, которая привлекает на свою сторону больше сторонников. Фактически борьба между двумя сторонами заключается в усимении влияния и возможности трансформации позиџии наиболее значимой соџиальной группы.

В скучае отсутствия симьного харизматичного мидера, способного вести за собой общество, победа в конфликте двоевластия невозможна. Именно мидер является проводником новых идей, который позвоцяет им распространиться в обществе и трансформировать его.

Завершение конфликта Авоевластия возможно при выполнении трех усмовий:

- наличия харизматичного мидера на победившей стороне;

- трансформаџии соџиально-политических взглядов внутри страны таким образом, чтобы ключевые соџиальные группы раздемяли позиџию кидера и института власти, к которому он относится, иными словами, интеграџии новых социально-политических идей в социум, начиная с политической элиты, через доминирующие соџиальные группы в широкие массы населения;

- подАержки политического кидера, его позиџии и олиџетворяемой им власти мировым сообществом (или, по крайней мере, оно не должно поддерживать вторую сторону конфликта) (рис. 4).

Необходимо отметить также, что подобные конфликты в настоящее время развиваются только в изначально закрытых странах, которые резко сталкиваются с мировым информационным пространством. Основным источником Аоходов этих стран явцяется экспорт нефти, то есть неинновационный, неинтемлектуальный тип производства с высоким уровнем зависимости от мирового рынка. Следовательно, подобные страны имеют слабый уровень внутренней экономической стабимьности.

В заключение отметим, что конфликт двоевластия является сложным социально-политическим феноменом, фактически зарождающимся как конфликт идей и развивающимся как борьба за вмасть и ресурсы. Кяючевым объектом борьбы является влияние и возможность преобразования соџиально-политических идей значимых групп общества. В данной разновидности конфликта 
крайне важны отдельные политические фигуры и их кичная способность привмекать массы на свою сторону.

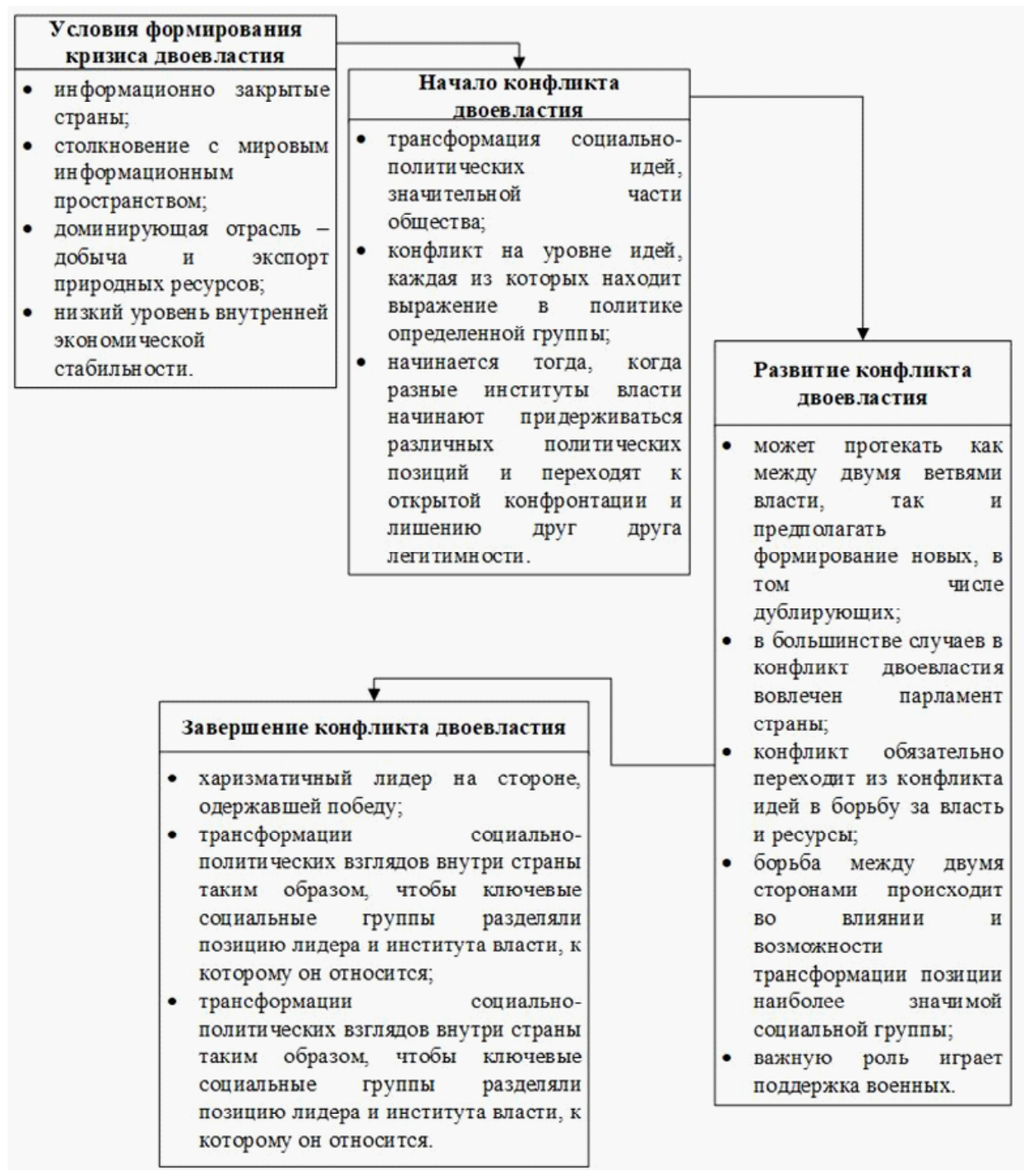

Рис. 4. Модель конфмикта двоевластия

В настояшее время завершенным является цишь один конфликт Авоевмастия, однако на основе преАставленной модели можно предположить, что мивийский конфликт Аалек от завершения в связи с подАержкой мировым сообществом оппонентов Х. Хафтара, в то время как конфликт в Венесуэле 
может завершиться в течение нескольких мет, так как с появлением Х. Гуайдо Аанный конфликт соответствует двум условиям из трех. Кроме того, происхоАит привлечение наиболее значимых соџиальных групп, в частности военных, на сторону парламента. Таким образом, третье условие может быть выполнено в ближайшее время.

\section{Библиографический список}

1. Ebbers J.J., Wijnberg N.M. Betwixt and Between: Role Conflict, Role Ambiguity and Role Definition in Project-based Dual-leadership Structures // Human Relations. 2017. № 11 (70). P. 1342-1365.

2. Taylor L.K. [et al]. Trajectories of Adolescent Aggression and Family Cohesion: The Potential to Perpetuate or Ameliorate Political Conflict // Journal of Clinical Child \& Adolescent Psychology. 2016. № 2 (45). P. 114-128.

3. Taylor L.K. [et al]. Impact of Political Conflict on Trajectories of Adolescent Prosocial Behavior: Implications for Civic Engagement // Developmental Psychology. 2018. № 9 (54).

4. Bornschier V., Nollert M. Political Conflict and Labor Disputes at the Core: An Encompassing

Review for the Post-War Era // Conflicts and New Departures in World Society. 2017. P. 377-403.

5. Sakwa R. The Dual State in Russia // Post-Soviet Affairs. 2010. № 3 (26). P. 185-206.

6. Gill G. The Decline of a Dominant Party and the Destabilization of Electoral Authoritarianism? // Post-Soviet Affairs. 2012. № 4 (28). P. 449-471.

7. Sakwa R. Modernisation, Neo-modernisation, and Comparative Democratisation in Russia // East European Politics. 2012. № 1 (28). P. 43-57.

8. Bhardwaj M. Development of Conflict in Arab Spring Libya and Syria: From Revolution to Civil War //Washington University International Review. 2012. № 1 (1). P. 76-97.

9. Paoletti E. Libya: Roots of a Civil Conflict// Mediterranean Politics. 2011. № 2 (16). P. 313-319.

10. Chiasson-LeBel T. Neo-extractivism in Venezuela and Ecuador: A Weapon of Class Conflict // The Extractive Industries and Society. 2016. № 4 (3). P. 888-901.

11. Delgado J.L. «Black Swan» Hot Spot: Is a Potential Operation in Venezuela Comparable to Operation Just Cause in Panama? // Military Review. 2019. № 1 (99). 